Florida International University

FIU Digital Commons

FIU Electronic Theses and Dissertations

University Graduate School

$11-13-2020$

\title{
The Power of Presumed Trauma and the Perpetuated yet Unintentional Silence in Henry James' The Turn of the Screw
}

Andria E. Rivero

Florida International University, arive360@fiu.edu

Follow this and additional works at: https://digitalcommons.fiu.edu/etd

Part of the English Language and Literature Commons

\section{Recommended Citation}

Rivero, Andria E., "The Power of Presumed Trauma and the Perpetuated yet Unintentional Silence in Henry James' The Turn of the Screw" (2020). FIU Electronic Theses and Dissertations. 4545.

https://digitalcommons.fiu.edu/etd/4545

This work is brought to you for free and open access by the University Graduate School at FIU Digital Commons. It has been accepted for inclusion in FIU Electronic Theses and Dissertations by an authorized administrator of FIU Digital Commons. For more information, please contact dcc@fiu.edu. 


\title{
FLORIDA INTERNATIONAL UNIVERSITY \\ Miami, Florida
}

\section{THE POWER OF PRESUMED TRAUMA AND THE PERPETUATED YET UNINTENTIONAL SILENCE IN HENRY JAMES' THE TURN OF THE SCREW}

\author{
A thesis submitted in partial fulfillment of \\ the requirements for the degree of \\ MASTER OF ARTS \\ in \\ ENGLISH \\ by
}

Andria Rivero 
To: Dean Michael R. Heithaus

College of Arts, Sciences and Education

This thesis, written by Andria Rivero, and entitled The Power of Presumed Trauma and the Perpetuated Yet Unintentional Silence in Henry James' The Turn of the Screw, having been approved in respect to style and intellectual content, is referred to you for judgment.

We have read this thesis and recommend that it be approved.

\begin{tabular}{c}
\hline Nathaniel Cadle \\
\hline Michael Grafals \\
\hline Michael P. Gillespie, Major Professor
\end{tabular}

Date of Defense: November 13, 2020

The thesis of Andria Rivero is approved.

$\begin{array}{r}\text { Dean Michael R. Heithaus } \\ \text { College of Arts, Sciences and Education } \\ \text { Andrés G. Gil } \\ \hline \begin{array}{r}\text { and Dean of the University Graduate School } \\ \text { and for Research and Economic Development }\end{array}\end{array}$

Vice President for Research and Economic Development and Dean of the University Graduate School

Florida International University, 2020 


\begin{abstract}
OF THE THESIS
THE POWER OF PRESUMED TRAUMA AND THE PERPETUATED YET

UNINTENTIONAL SILENCE IN HENRY JAMES' THE TURN OF THE SCREW

by
\end{abstract}

Andria Rivero

Florida International University, 2020

Miami, Florida

Professor Michael P. Gillespie, Major Professor

Henry James' The Turn of the Screw (1898) has long been a work capable of numerous interpretations and readings centering around the lead character, the governess, and her intentions and interactions in the novella. However, this thesis explores the extent of the governess's actions and power and their results towards the children for which she is responsible. In this thesis, I focus on the presence of trauma as presumed by the adult characters, perpetuating unintentional limitations on the children who are assumed to be traumatized. The thesis uses trauma studies to understand power dynamics within the novella. The power dynamics between adults create a culture of silence that isolates and hinders the potential of understanding knowledge for those assumed to have undergone some form of witnessing to the mistreatment. 


\section{TABLE OF CONTENTS}

CHAPTER

PAGE

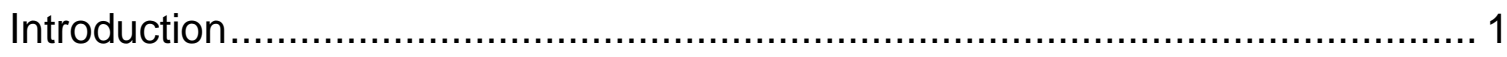

Understanding Silence in Trauma: An Overview ............................................... 5

Presumed Trauma and Unintentional Silence Created by Adult

Power In The Turn Of The Screw ................................................................... 12

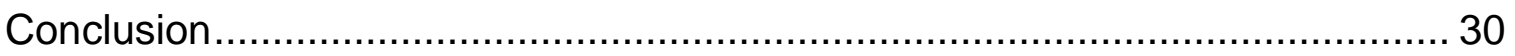

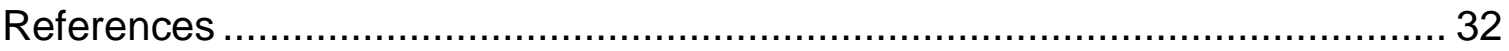


Introduction

For over a century since its initial publication, Henry James's most famous work, The Turn of the Screw (1898), has been a subject for academic inquiries and popular interpretations. The most common debates revolve around the accounts and condition of its narrator, the governess. Critics tend to focus on the question of what she has seen whether it be spectral visions or hallucinatory experiences. Such views have become known as the apparitionist versus nonapparitionist interpretations of the text. These readings are valid on the grounds that James's writing styles consistently evoke ambiguity, lack of consistent evidence, and unreliable witnesses.

The narrative is already a vessel with boundaries that may only provide brief glimpses and ambiguous clues that validate numerous analyses. In turn, the same evidence could be used to invalidate other analyses. However, in the grand scheme of The Turn of the Screw interpretations, the most affected and changed characters are Miles and Flora. However, they are relegated in the background in favor of discussions held around the adult subjects, their motivations, and their relationships with one another. As the text is already being written in the governess's perspective, that must be considered. Readers and critics alike are then subjected to treating the children as having been, presumably, through certain traumas done by their previous caretakers, Quint and Miss Jessel.

The Turn of the Screw is framed by a Christmas Eve party, by which numerous tales and anecdotes are shared, as a 'ghost story' contest is 
underway. Douglas, now wanting to share his ghost story, presents a series of private writings from the original writer, the governess, who has long since passed away. Therefore, the tale is the recounting of a young governess who entered an isolated manor known as Bly, owned by the never-seen-again master who hired her for his niece and nephew, Miles and Flora. Upon first arriving at the manor, the Governess understands that the older Miles is away at boarding school while the housekeeper, Mrs. Grose, has been attending to the younger Flora. Under strict rules and guidelines created by the children's uncle, the governess cannot make any contact with him, and she has been left the responsibilities of child-rearing. What then follows is the governess's journey to understanding the past events that transpired at Bly. What sets this series of inquiries off for the governess is a letter received at Bly about Miles's expulsion from his boarding school. After Mrs. Grose's franticness and assertion that Miles would have never acted in such a way to warrant such a punishment, the governess and housekeeper vow never to respond to the letter. It was important for both characters to never bother the Master and this has been a recurring reaction later in the novella.

However, after Miles's arrival, the governess attempts to gauge the situation and learn of the specifics as to why he has been expelled. But a disconnect forms from what little Miles explains of the situation to the governess and how she perceives him as more than angelic and innocent. It is soon after that the novella's infamous figures appear around the governess. She frequently spots an unnamed man and woman around Bly. Their presences were not 
disruptive to the household's everyday matters; however, they are either traversing or eerily staring through windows. Instead, the only one to take issue and notice them is the governess, and these figures freely and calmly roam throughout the property, much to her dismay. After confronting and questioning Mrs. Grose on the matter, the governess concludes that the figures she sees are, in fact, the former caretakers of Miles and Flora, Quint and Miss Jessel. In the revealing conversation with Mrs. Grose, certain facts come into light about the relationships between the caretakers and children, what the caretakers were like, and what has become of them. Such details would include the caretakers being in a relationship together, their closeness with the children, along with the caretakers having died suddenly. All this leads the governess to do is further conclude that these figures wish to possess the children. It is from here that the governess continues her investigation into the matter, while also raising the children and keeping a close eye around for the spirits. Meanwhile, the children begin acting strangely once this information is revealed to her.

As one may already tell, the governess's position at the head of the narrative means that the focus will be drawn to her and her assumptions she has made because of what she witnessed at Bly and what she heard happened at Bly. Her interactions and conversations are crucial in allowing passage for any observations, clues, and information that can be made about the current events and past happenings at the estate. However, as a person who controls the perception of events on paper, she also had power in Bly's living situation in how she interacted with both staff and children. 
I develop the point that trauma is prevalent within The Turn of the Screw by the fact that the adults in the text, the governess and Mrs. Grose, presume that the children, Miles and Flora, experienced trauma. More specifically, the governess' conclusions made after talking to Mrs. Grose, and her active assertions of these presumptions unto the children, can present a possible response as to how The Turn of the Screw can be read as a horror novella. In the case of the novella, the societal horror would take The Turn of the Screw as a text of trauma, and the limitations placed around trauma holders by those who are witnesses of trauma, be it directly or through the transference of knowledge. The significance of my paper lies in understanding how much interpretative power James provides his readers. It is only a sample of many readings that can be built primarily through theoretical backing and work from what the story provides. 


\section{Understanding Silence in Trauma: An Overview}

In this section, an overview of trauma study through the lens of Cathy Caruth and Shoshana Felman will be explored. What is important is understanding the dimensionality of trauma. To comprehend trauma, one has to recognize what may cause trauma, if the trauma is an active variable in someone's life, how it can and may affect others outside of the event, and the transference of trauma. These questions are significant for this portion of the chapter and further conversation when used in tandem with The Turn of the Screw with assumed trauma within the novella. Afterwards, the concept of "culture of silence" will be introduced to better explain the dynamics of adult powers over the children within the setting of the The Turn of the Screw and how it has been implemented through the assumed trauma that the children underwent.

The culture of silence is a system created, preserved, and maintained by the unification and direction of like-minded individuals of any variation of size, and other identities, who unanimously agree and practice avoidant tactics in not expressing, acknowledging, and alluding to a particular subject matter. The expression, culture of silence, alone gained traction across U.S. news platforms and movements, like \#MeToo, in challenging power structures and entities like in the Weinstein case and Epstein investigation. Silence as an obstacle and power as its perpetrator has already been a common theory in organizational psychology and began in the 1980s through justice theory (Nikaeen, Jobtaba and 
Bagheri, Ghodratollah, 2012). Francesca Gamabrotto and Alberto Cammozzo address the phenomenon where silence better demonstrates "approval and sharing or disfavour and opposition," which therefore implicates and creates a tense setting between employees and the organization (4). Regardless of its use, the byproduct remains the same: an avoided topic.

The cognizant effort to retain control and the subliminal denial in voicing an opinion means that a gap exists in dialogue, which is to say that the gap is something, or someone, largely repressed from expression. In consequence of this absence of expression, what remains of authoritative abuse is the trauma for those excluded. The experience of trauma through silence is a relationship long withstanding for as long as power has existed. However, the trauma behind power and silence is one that has been a study of intrigue for over two decades.

Unclaimed Experiences (1996) by Cathy Caruth embarks on reconstructing Sigmund Freud's psychoanalytic concept of "traumatic neurosis" a repetitive and uncontrollable return and reenactment of the traumatic event by the survivor without their recognition. It is a multifaceted experience and language that not only has one designated path of understanding but takes on a surrounding coexistence in how survivors bear witness and transmit their understanding of their trauma. It is not the visceral reality of their experiences that eludes and haunts the survivors in the stories. Their unawareness of their trauma and how the violence unknowingly impacted them is what haunts them (6). History is not an impasse between the survivor and their actualization. 
However, through their transmission and the paradoxical indirectness with trauma, the person's consciousness persistently distances them from the event(s), which happens without their formal awareness (62). The survivor handles what they perceive as reality consciously, as their unconscious handles day-to-day rituals. Between these two, there is a threshold where one does not cross the other. The subconscious does not speak to the conscious. The mind's limitations are consistently how the brain is structured for adaptability and efficiency for the long-term, not short-term.

The consciousness is the mediator between body and knowledge, which marries an emotion and time (or event) to simulate and experience through recollection (Caruth 63). However, any threat to the body creates an irregularity to the consciousness to the point in which a shock overwhelms the body and breaks the lapse of time and sensation (Caruth 64). The break in the system shifts the consciousness urgently to continue as normal, rather than register and assess the preceding event that caused its disturbance. It was a matter that is viewed outside of normal time but seen as a hazard that occurred untimely, which the mind must work around. What proceeds is that a lacuna is etched into the mind, causing unwitting recurrences because the pathway from knowledge to the body has been effaced. Caruth describes the process as the "repeated confrontation with the necessity and impossibility of grasping the threat to one's own life" that a survivor undergoes through trauma (64). The fixation of trauma for Caruth in different media is that the center of trauma does not solely involve the mind post experiences and its effect. It entails trespassing the threshold 
created by the consciousness that wishes to speak but does not know how to speak. Therefore, silence is created. The silence links the direct presence of trauma to the indirect behaviors and language (Caruth 4). Alongside the interior factors that create this tense silence, exterior factors can mobilize or immobilize the trauma holder. These factors can break the barrier, which may engage more numbers than just one survivor.

While history is a persistent variable that is already predisposed to ethical and political elements, it can be altered when immediate memory cannot. The value of history through trauma is by the fact that it links others across location and time. Trauma can happen from personal to collective memory, involving groups that may or may not be aware of their connection by the persecution they received or witnessed. While the recorded history designates a sanitized overview of larger events dubbed important by historians and archivists, the referential point that should be approached is the one that is already difficult by its occurrence (Caruth 19). Although trauma listeners were not there to bear witness to the trauma, the culture of silence persists through indirect comments but not direct acknowledgement. A rhythm of repression and returning happens where displacement exists. When trauma returns, witnessing plays an imperative role by how history is spread. It is in this history of movement between the two that "remains...absolutely opaque, both to the one who leaves and also to the theoretician, linked to the sufferer in his attempt to bring the experience to light" (Caruth 23). 
Testimony: Crises of Witnessing in Literature, Psychoanalysis, and History (1992) by Soshana Felman and Doi Laub, M.D. approaches trauma studies through the hybridization of incorporating testimony, witnessing, and memory in lieu of reviewing the history and one's involvement and awareness of the events that were undergoing, be if they were the primarily involved party or not. With the many forms in which witnesses can occur, there is a point of access to reality and testimony. Accessibility is possible through the transference of knowledge by memory. However, the biggest hurdle to overcome after being a primary connection and harbor of knowledge will then be securing and preserving the trauma, which in this book is explored through being in different media like literature, film, and art. Movement of knowledge, for Felman and Laub, is important when pursuing this growing web of transmission as "the development [is] based in the increasingly articulate pursuit, and in the increasingly complex progression, ...by the exploratory structure and process of unfolding" (xv).

By becoming a witness through transference, a paradigm causes shiftsin two realities, personal testimony and history, for both a trauma holder and the trauma listener. It is a case of an event that was not recorded accurately to its history and was already altered by the time of its original preservation. In certain cases, it may not be deemed worthy of acknowledgement or was deliberately hidden. The act of witnessing one's trauma cannot always occur because trauma and the knowledge of having undergone trauma do not happen simultaneously. At times, an individual may have one over the other. Being already inside the event means that there is not a true possibility that the person carrying trauma 
can step outside this reference and create themselves as their own witness detached from the setting (81). No event can have a witness to the truth of trauma by the fact that all sides cannot be attested for, yet there are fragments capable of being held onto and transmitted through means of communication, media, and record.

Synthesizing all information and newly formed ideas based around trauma, the thesis will therefore be taking on the following ideas to be used when mentioning trauma:

- It can happen at any time and any place, but that does not necessarily mean the trauma holder will remember that time and location.

- It can take on many forms of alterations to the person's psyche, behaviors, rationality, and memories.

- It is not a "knowing" experience for trauma holders to have, and there are trauma holders that can live through life without realizing and understanding that what they have experienced is trauma or that they have gone through trauma.

- Its effect does not only impact trauma holders and does not have a singular route. Those who gain awareness of trauma, and even if they have not directly experienced it, are witnesses of trauma by the act of transference. 
- Inheriting trauma can take on many forms and can have many effects that will always create an alternative viewing of reality.

- There are cases where people uninvolved with the trauma that someone has undergone are aware of it. They are as responsible for trauma as those who traumatized the individual but in a different sense. Witnesses can impede the trauma holder or help them understand and create a sense of what has happened to them. 
Presumed Trauma and Unintentional Silence Created by Adult Power in The Turn of the Screw

Now, The Turn of the Screw has already seen countless interpretations and readings that will always return to and focus on the governess in part by the fact she is the only source of knowledge any reader will receive about Bly. In this section, we will investigate the concepts of power that already exist in the text between the dynamics of Mrs. Grose and the governess, the anxieties perpetuated by the established environment made by their absentee superior, and how their desire to appease their superior's orders ends up silencing Miles and Flora because of presumed trauma.

Accounting for the nature of implications in both James's writing style and the governess's private writings, readers, critics, and the governess herself are coasting through understanding and becoming witnesses for the assumed traumas that Miles and Flora underwent at Bly. The transference of the knowledge that the children have undergone an unnamed trauma is paralleled by the governess's understanding and by the audience's understanding. More specifically, the governess' written character does not witness complete and real events of the situation surrounding the novella. Instead, we need to observe that the current events at Bly, through the written governess, is reflecting her process of understanding and synthesizing information. Such a process is one that the readers are undergoing too while reading her account. The governess's actual character, being the writer as opposed to the written character, made the 
deliberate decision to disclose information and details into her own controlled setting. However, her writings were not planned to be read at any point soon by anyone else other than herself. Her intimate writings are already not objective, and her perspective is already angled from having a clear lens.

Taking in everything, the governess is the prism by which the events at Bly have been retold. The inherent truth is that our observations and conclusions into the text will always be not in our hands, but in the hands of the governess who holds narrative power. Meanwhile, James holds creative power in how, as the author, he creates this pathway between reader and narrator. It is natural then for the focus to go to the governess and her predicament. To believe the importance of the novella is about her state of mind, and not about the children, is a result of this. However, some gaps need to be addressed as, ultimately, there is more to the story than the existence of ghosts.

Edmund Wilson, a vital figure and pioneer in analyzing The Turn of the Screw and other of James's works, cemented that multiple interpretations, including a psychological and sexually repressed reading on the governess, were possible. For him, Henry James "carried his ambiguous procedure to a point where [the readers] almost feel that the author does not want [them] to get through to the hidden meaning," which includes whether the apparitions were the villains in the novella (99). However, the flaws of psychoanalytical reading include amplifying the sexual repression Victorian women faced as sexual promiscuity was already largely silenced and ostracized. Compared to the higher 
class, which owned property and defined morality on the basis of their political and financial power, the lower class was commonly subjected to being controlled as a means in securing society. Through the psychoanalytical reading, class and gender differences intersected between the role of the governess and her relationship with the high-class unnamed uncle (commonly referred to as "Master" in the text). The passions expressed between the deceased caretakers, and noted by Mrs. Grose, were already frowned upon. Because of their different social ranks, their relationship did disrupt the social order and construct that divided class. An interpretation of why the governess saw their ghosts, in the psychoanalytic lens, would then be out of jealousy, for she could not pursue the same type of relationship with the uncle. By overvaluing moral security, the dominance of passion and desire will bleed into an individual's self-control and objectives. Thus, creating the cycle of frustration that produces projections from the governess's imagination.

However, the psychoanalytic reading confines the horror to be exclusive in the governess's mind. The Turn of the Screw as a horror novella would, instead, focus on her psychological profile and label her downfall from sanity that began with her infatuation with the "Master." While the psychoanalytical reading shares the same roots for a non-apparitionist reading, limitations arise. Such restraints include how the children, the common thread shared by all the adults in the story, are objectified and stripped of their character positions and experiences. To only become fixations in the text only means that their trauma and encounters become secondary and their losses were avoidable, had the governess not 
overstepped Victorian boundaries, and indulged in her thoughts of sexual curiosity. The presence and assumptions of sexuality in the text, for the Victorian era, however, does make sense when considering that this period had an interest in exploring purity when relating back to a child's sex and age.

Victorian England was among the most restrictive and careful cultures that esteemed order at all intersections, including race, wealth, education, gender, and age. Nineteenth-century England seemed to have no designated points of protection for minors against sexual abuse was possible by the conversation of gender roles. Lawson Tait, a famed gynecologist, argued that "male sexual behavior was generally expected to be active and predatory" (Jackson, 83). However, Tait persistently devalued the arguments and defenses of impoverished children as lies since "poverty and social position were proportional in his eyes to corruption and sexual precocity" (Jackson, 84).

Inspecting and understanding a child's body followed the common ideas of innocence and naivety. Bodies that were not ruptured or showed signs of maturing (girls menstruating, for example) were the essential image of a healthy child. Since their bodies do not naturally have orifices associated with childbearing, when examined, male bodies were seen to be visibly unchanged unless they were sodomized. However, the biggest qualifiers for sexual abuse in texts and medical research throughout the time dealt with penetrative acts. Reducing the trauma to only include adult-on-child predatory acts means large gaps in legislation existed for children who might have been instructed and 
groomed by their perpetrators to perform acts on themselves, other children, or other adults.

To supplement this idea would be the malicious interpretation that the governess has in understanding the visions of the former caretakers that she is seen. The first of ghosts encountered happened to be Quint's ghost. Mrs. Grose, the housekeeper, declared that it was in "Quint's own fancy...to play with [Miles], I mean—to spoil him," causing the governess's face to distort with disgust (43). However, the "disgust" that the governess has against any of Miles's other relationships, outside of the family and other house workers, has appeared before. Upon their first direct meeting, the governess remarks that "he never spoke of his school, never mentioned a comrade or a master; and [she], for [her] part, was quite too much disgusted to allude to them" (32). Her own reactions stemmed from her perspective that the innocuous young Miles was above the accusations and that he was not capable of behaviors that would have gotten him expelled from school. Her approach reflects a lingering understanding and disdain towards another figure of power in Miles's life. Already, at hearing the news of Miles's expulsion and Mrs. Grose's shock about the news, the governess has already sided with the children. Though, as ambiguous as the text is and how little is given about these circumstances, the governess's reaction shall be related to how she responded to Quint's relationship with Miles. Ergo, there is an implication that her disgust pertains to the baseless accusations against Miles since there has been an insistence of him "[having] been wicked" (31). Quint's ghost and his behaviors, according to the governess, has malicious intentions 
and an evil nature that unsettles her during her time at Bly. As he looms and does not speak to anyone, the governess is conclusive that Quint's ghost, though having not approached anyone, wishes to harm. His gaze was "the same, and seen, this time, as he had been seen before, from the waist up, the window," keeping his approach indirect but authoritative by disrupting and unsettling the governess (33). Because of that encounter, she believes he (along with Miss Jessel's ghost) will try to possess the children.

The case of Quint can be seen as someone who disregarded and crossed boundaries that were against the culture, such as power and sex. Mrs. Grose informed the governess that he was "too free with everyone," only clarifying after the protagonist was repulsed and specified in her inquiry: "too free with [her] boy" (43). The other tutor, Miss Jessel, was noted as being "infamous" by the housekeeper and in a relationship with the other carer. By Mrs. Grose's own account, Quint "did what he wished," not only with the former tutor, Miss Jessel, but with everyone else on staff as she emphasizes "with them all" (52). With the same results, the text accentuates that both caretakers are together with their respective students. When confronted by Mrs. Grose about the relationship, the housekeeper is conscientious of Miss Jessel being from the higher class, and the tutor "had, with a most strange manner, requested [Mrs. Grose] to mind her business" (58). With the lack of secrecy between the adults being in a relationship and Quint's promiscuity and openness, there is now a connection extending between the provocative and the innocent. However, there is a lack of information regarding Miss Jessel's background and interactions with the 
household. Meaning, while there are is persistent reference and description of Quint's infamy in the household, Miss Jessel's infamy is not as visible in the text. There are not as many present ruptures in the narrative that gauges her relationship with Flora in the same way that Quint and Miles can be gauged. However, the lack of ruptures does open the possibility that Miss Jessel cooperated and functioned as a synthesizer for Flora, only doing what an instructor needed to do and helped her learn new things.

We are now left with the questions of how to approach the novella: is it a cautionary or tragic reading, and who is it a warning to, and who is it tragic for? If it is about social commentary in Victorian England and the downfalls of nationalistic anxieties, or a morose tale of a young woman unable to combat the evils that befall the children she was meant to protect, all paths share one similarity. Ergo, the fact that Miles and Flora are quintessential to gauge the governess. They are of the utmost importance because of their impact on the governess since A) the governess reacts and works around the children to investigate what occurred at Bly and B) her official title requires her to educate and socialize the children. Their behaviors and backgrounds, after all, are what fuel the governess to investigate further and then find validation into what she is witnessing at Bly. However, as devoted as she is to her job, the governess is still a retainer of power that has precedence over the children, which may have left to depowering them both. 
A governess, in terms of power dynamics, serves as feminine and domestic power within a household, and this is important to understand before partaking in discussing the Bly's household dynamics. Highly privileged and wealthy families would hire a young, unwedded woman in her early twenties. She would be responsible for teaching the children of the household. Her role differs from the role of tutors, who focus mainly on the scholarly end of education. While also teaching children the basics like writing and reading, the governess also taught the children socially acceptable behaviors and abilities (i.e., speaking a second language or playing an instrument). The governess is a newly introduction role of power for the children. But her powers have its limitations. She acts as a stand-in for the children's guardian, as being an adult that is present and watches them, but she has no power over them and cannot reprimand them. A governess as a position of power within the household is unique because they were exceptions to the common rule of how femininity and work were understood not to be compatible in the Victorian time.

Victorian governesses are the primary connections and first-time exposure for most aristocratic children to the outside world. As well, they are the first indicator of the socially acceptable and unacceptable behaviors that are allowed - children observe and act according to the governess. The position of power for the young governess exists between servants and wealth, given that those hired for such positions come from a similar background of education, wealth, and privilege like their superiors (Peterson, 15). In the same way that she is addressing social education for the children, she is also the living example of 
how social dynamics and roles work according to what the era found acceptable. Her connections to the outside world are strictly limited, if not impossible, to continue during her time of employment. Though, her priorities and duties revolve around the isolated space of English social life that is ever more private and never to be public towards anyone else that does not have permission.

However, as far as a governess's social standing is regarded when employed, her position's difficulty and anxieties are one that are "incongruent" to that of the pre-established and normal roles in the home (Peterson 20). At the ages that a governess is needed, children are taught and sculpted by the traits and lessons that their guardians have presented - intentionally or not. Having an outside force within the household paves the way for a new possible power to criticize, if not expose, the truth behind the idyllic idea of the Victorian household. Yet, with her background, a governess does not have any social standing above the staff. While she is served and tended to by the household staff, she does not have any designated power to order them (Peterson 17). Therefore, a governess is in a uniquely sensitive situation. Her actions can be scrutinized and criticized by two parties: the wealthier end, being her employers, and the impoverished end, being her not-so-true coworkers.

Meanwhile, Mrs. Grose, the other and only named living staff at Bly in the governess's private writings, is the governess's primary ally and confidant at Bly. Mrs. Grose's circumstances are that she is the housekeeper who is already experienced and dealt with the children while the valet and tutor were still alive. 
Her prior care experience has been to take care of Miles and Flora's ailing grandmother before their arrival at Bly. While the governess may be our focal point into the mystery of Bly, Mrs. Grose is the clarity that the governess may look at the preceding events and relationships involving the children and Bly. Any form of inquiry that arises during the governess's initial viewings of the figures lurking on the estate is answered directly by the housekeeper, leading to communicating and creating ideas that may or may not be true to what has happened.

During the first encounters between Mrs. Grose and the governess, what is essential to understand was how the manor works. More specifically, how information could never be disclosed to Miles's uncle with excuses of "[not] liking tale-bearing" and "the master believed in him [Quint]," which means the servants are compromised. Quint, in the uncle's good graces, is already absolved from problem. A barrier is then created and becomes a predicament for those of lower status (the servants) versus the former valet. What lies in the balance is the loss of their job and the lack of success in telling if they had any choice since they are without power. With the potential to disrupt the master's social connections, domestic workers who were aware of Quint's behaviors and actions may have chosen not to speak, on account of the cons versus pros. They were placed in a double bind, injuring the subservient person, and involved parties, no matter which route they choose. 
To exchange naivety for knowledge was costly for the governess. Mrs. Grose provided background information about Miles's former valet, Quint, after the governess reportedly saw him stalking around the manor. The housekeeper noted Quint's interactions with Miles, noting that he'd like to "play" with him, before correcting herself to say "spoil" him. While previously noting the governess's response to the statement, being her reacting with disgust, what stands important is the active correction Mrs. Grose makes. By switching between "play" to "spoil," she is redefining the actions between both valet and child. This carefulness of rephrasing the dynamic, though as already ambiguous as it is in the text and what little is given around this relationship, what we can understand already is that there is conscious and deliberate effort to create a specific image of their bond. This active revision would also contribute to why the governess responded the way they she did. Meanwhile, for Miss Jessel and Flora, the only known fact was that Miss Jessel was of the higher class, noted as "infamous" by Mrs. Grose, and was in an affair with Quint. Through her recognition, the governess began gaining consciousness of the situation at hand between the children and caretakers, though those relationships' details are left ambiguous.

I forbore, for the moment, to analyze this description further than by the reflection that a part of it applied to several of the members of the household, of the halfdozen maids and men who were still of our small colony. But there was everything, for our apprehension, in the 
lucky fact that no discomfortable legend, no perturbation of scullions, had ever, within anyone's memory attached to the kind old place. (43).

Quint's disruption of the social structure and unusual behaviors were known throughout the household, and nothing was said about it. For the outside world, Bly had not a stain on their record from the provocative figure who played "too freely" with everyone and even struck fear in the housekeeper if she ever dared consider speaking up. What has now been created is a doubling between Bly and all its residents' actual status and image, now including the governess. By delving further into the mystery of the children and learning of their situation, she is now an active witness to the effects of the trauma that the children may or may not be aware of.

What it was most impossible to get rid of was the cruel idea that, whatever I had seen, Miles and Flora saw more—-things terrible and unguessable, and that sprang from dreadful passages of intercourse in the past. Such things naturally left on the surface, for the time, a chill which we vociferously denied that we felt...(87).

While the governess speculates how Miles and Flora were witnesses to atrocities that went against their innocence, one of the questions remains on whether they have been able to recognize these horrors. Unlike the children, this creates a rift 
with the readers as they must consider the safe space that the children were not in.

Despite the Master's absence at Bly, power is a strong force within the household; the manor, including the inhabitants, takes the embodiment of a panopticon. With the invisible figure prompting worry in the staff, the silence is used "to alter behaviors, to train correct individuals" that maintains the image of stability (Foucault 8). In turn, the system of power has now created a façade that the staff performs to avoid acknowledging Miles and Flora's mistreatment. When the children are treated differently, they will then realize that they have been altered and may not know why. Caruth explains that trauma returns because of "its very unassimilated nature," and, despite trauma not having one place of origin, it will return in different forms (thoughts, behaviors, coping mechanisms, etc.) that will "haunt" the survivor (4). Even without the explicit details behind the relationships between the caretakers and students, Miles and Flora themselves are haunted. The ghosts do not haunt them the governess claims to see, but they are haunted since someone has given brief awareness without proper explanation. The governess appoints herself to "serve as an expiatory victim and guard the tranquility of my companions" (44). Her over cautionary, borderline coddling nature creates the difference that the children could then react to in their awareness journey. However, as the governess is determined to keep order within the household and prioritizes the "tranquility," she thus serves as a similar silencer like the original Bly Manor staff. The panopticon, in the novella, "does so not [hold] power itself...its aim is to strengthen the social forces - to increase 
production, spread education, raise the level of public morality; to increase and multiply" (207-208). The governess of Bly holds the same responsibilities as the panopticon. She must represent the state of constant vigilance and visibility that enforces others around her -- mainly, the children - to act appropriately. Her awareness of the children makes her reform her own behavior and readjust herself to continue this representation that she must hold in her position.

The governess's greatest challenge in her sleuthing has been her rationalization and theorizing behind why Miles was expelled from his school. He described it that what he said were told to those whom he liked, genders never mentioned, and what he said traveled through to the masters of the school. Intriguingly, he mentioned that the other students "must have repeated them to those they liked," meaning that at one point, there was an adult-child interaction where one "liked" the other (146). Given the openness of Miles's relationship with Quint, where the valet freely spoke and supposedly knew no barriers and restraints in conversation, the implications he shared with those that he liked is seen as romantic. It matters not as to whom he shared it with by their gender, but it matters how he expressed it that led to his suspension from school. With the previous hostility and confirmation from Mrs. Grose regarding the valet, Quint's explicit nature could have been integrated and altered Miles's perception of the world. It is something that the governess notes when observing the siblings' strange behaviors, including Miles lurking in the garden with Flora watching him to Flora rowing a boat in the middle of the lake without anyone noticing. 
Ultimately, the governess's main function in the household includes caretaking and childrearing. She is within the role of examining and drawing comparisons between the socially acceptable and enacted from the children. Her own persistence to unravel the mystery behind what happened at Bly, or more so, what happened to both Miles and Flora has been framed in guilt. As previously discussed, Mrs. Grose has not ever taken full responsibility for the children, and outright declines any active participation. Her own excuses were leading that the caretakers were acceptable parental substitutes. She expressed the same grievances and honesty when she vaguely alluded to said valet and tutor's past. However, the governess describes her subservience through religious diction, needing to "serve as an expiatory victim and guard the tranquility of my companions" (44). Alas, it is not guardianship that she is alluding to when she expresses herself as an "expiatory," or a sacrificial victim who will protect her companions, be her friend, or the children.

Trauma in The Turn of the Screw can alter already pre-existing readings that may draw an important difference in the concepts of the other figures, Quint and Miss Jessel, in the text. Those directly affected by trauma are those who assume that such an experience occurred. Those directly affected are the adults, also known as the trauma listeners. However, they are trauma listeners only through the fact both communicated and transferred knowledge that is implicative but not definitive as to what may have happened. Doubled on the fact that both women are responsible for the children, the adults are at an intersection of how to proceed with the presumed trauma. As already established, the governess 
abides by the Master's rules and operates uniquely in a space where she does not retain her aristocratic privilege, but she does not have it removed. Her modus operandi puts the children above herself than all else and bestows them socialization, education, and stability as impressionable youths on their way into the growing world. Any previous behaviors and traits that are ineffective and harmful to their future education and places in Victorian society are detrimental to the governess's goals and reason for being hired.

Quint and Miss Jessel's relationship with Miles and Flora are perpetually ambiguous to the degree that they are analogous to whatever the audience reserves that relationship to suit their personal terrors. Sexuality, queerness, classism, and satanism are among examples of how the relationship has filled. It is determined not on direct quotes, but on structures within the text that, instead, confirm differences, including examples like Quint and Miss Jessel's relationship and Quint's background as below-class compared to the children's uncle. Regardless of how the figures can be interpreted in the text, be they hallucinations or specters, they carry the same underlying connection to the governess that relates to her awareness. The awareness that the governess carries already is this presence of knowledge that involves the children and their presumed trauma, and the presumed people responsible would then appear because of both their relationship to the knowledge and the literal relation to the children. 
The intentions of the spirits (or hallucinations) are already altered through understanding that trauma can be read through the novella. Versus the fear of the governess believing that the ghosts are hunting and wanting to possess the children, the spirits may also be linked to the children through the subconscious connection made by the transference of knowledge. To be more specific, the intentions of the figures in the novella harkens back to Felman and Laub's emphasis on motion and trauma through witnessing trauma. While the children may not be conscious of what trauma they have undergone, there is always the potential of relapse and being re-exposed to the trauma in ways they do not fully understand. Because of that cycle, like the cycle of ambiguity in James's writing, the ghosts can function in two ways. Instead of ghosts wanting to possess the children, and the children being actively aware or in danger, the governess instead sees visual reminders or even spirits hanging around the children. Likewise, as the trauma listener, the governess is given access to a unique space to perceive the children, creating an alternative reality to the one the children are living. Like described before, they may be ghosts by way of the children's trauma being their anchor to this world, or they are hallucinations perpetuated by the knowledge of presumed trauma. Similarly, the ghost of Quint can be read as predatory, but he can also be read as looming and present without malicious intent. After all, it is only through the governess that these figures are prescribed their malicious nature, perhaps because they may be detrimental to her plans. 
At the governess's discretion, she remarks the figures as entities that are posed to harm the children and lead on a crusade to protect their children which soon works against her as Flora is sent away from Bly and Miles ends up dying at the end of the novella.

What it was most impossible to get rid of was the cruel idea that, whatever I had seen, Miles and Flora saw more-things terrible and unguessable and that sprang from dreadful passages of intercourse in the past. Such things naturally left on the surface, for the time, a chill which we vociferously denied that we felt... (87)

While the governess speculates how Miles and Flora were witnesses to atrocities that went against their innocence, one of the questions remains on whether they have been able to recognize these horrors. Unlike the children, this creates a rift with the readers as they must consider the safe space that the children were not in. According to Kenneth B. Kidd, "the [audience] must now witness trauma, somehow 'remember' it without necessarily being there" in historical children's literature in order to create empathy and create the first-hand experience to witness the horrors (190). Readers must now place together with the unresolved story alongside the governess to unravel just how aware the children are of their abuse. Without any protection within the household and lack of power, Miles and Flora were ultimately isolated from aid and left alone to handle their trauma. With no power to fully discover the secrets of the past, the governess must now 
function as the guardian that protects children's innocence that was questionably ruined without their knowledge. She believes by the Victorian culture that she is in the right to further isolate the children from recognizing this (i.e., she fears that the children would get possessed by the adults' ghosts, meaning that they would have accomplished full exposure and awareness).

Conclusion

Much like other interpretations of The Turn of the Screw, a trauma reading of the novella may provide as much, or if as little, an entry point into Henry James's work that answers all questions and plotlines presented throughout the text. The conversation of evils, possessions, and terror can take upon another form in the text through this reading and does not entirely exclude other readings that hinder whether or not the 'ghosts of Bly' are true and the true intentions of the governess. James's true intentions for his novella will, as always, never hold to a particular truth above the rest, but there are still avenues of interest that can be explored into the novella that have yet to be truly engaged with. Trauma, as an avenue, is a way to go about The Turn of the Screw. It can be through a pedophilic reading between Miles and Flora and their former caretakers or the governess's relationship with Miles or through a reading of exile and isolation by the fact that Miles and Flora's parents (and their substitutes for parents) both died when both were undeniably young and were immediately removed from a familiar setting overseas to the isolated Bly estate. Trauma itself already does not need to have a physical presence in someone's life and can be created through 
cultural and ideological fundamentals clashing and altering one's humanity and perception of the world. A possibility of reading is possible if we consider the origins of the governess and Miles and Flora. The governess as a stand-in for Anglo-Saxon anxieties in 19th century Victorian England versus the children being representative of future British generations that may not have roots directly in the British empire and are, instead, raised elsewhere and changed byways of other cultures being present (in this case, India for the children) is possible. However, this is taking a new lens of this idea that was not entertained nor explored properly throughout this thesis. It is crucial to note that those who both read and listen to the governess's private accounts have also now become inheritors of trauma. Be it if it is the governess's trauma of what she witnessed at Bly or the indirect and implied trauma that the children underwent, we are now possessors of knowledge, and how we handle it is reflective of the next generations of trauma inheritance. This is not only a burden but a power, a position we also hold that parallels the governess's position. Moreover, what matters, in the end, is what we do with this power and how that may either aid or harm someone or a larger group of people. 


\section{References}

Bates, Victoria. "The Legacy of 1885: Girls and the Age of Sexual Consent." History \& Policy, 8 Sept. 2015, www.historyandpolicy.org/policypapers/papers/the-legacy-of-1885-girls-and-the-age-of-sexual-consent.

Caruth, Cathy. Unclaimed Experience: Trauma, Narrative, and History. Baltimore: Johns Hopkins University Press, 1996. Print.

Fee, Elizabeth. "Psychology, Sexuality, and Social Control in Victorian England,." Social Science Quarterly, vol. 58, no. 4, 1978, pp. 632-646. JSTOR, www.jstor.org/stable/42859921.

Felman, Shoshana, and Dori Laub. Testimony: Crises of Witnessing in Literature, Psychoanalysis, and History. New York: Routledge, 1992. Print.

Foucault, Michel. "Panopticon." Discipline and Punishment, The Birth of the Prison. Trans Alam Sheridan. New York: Vintage Books, 1979. Pp. 200-209.

Gambarotto, Francesca, and Alberto Cammozzo. "Dreams of Silence: Employee Voice and Innovation in a Public Sector Community of Practice." Innovation, vol. 12, no. 2, 2010, pp. 166-179., doi:10.5172/impp.12.2.166.

Jackson, Louise A.. Child Sexual Abuse in Victorian England (Women's and Gender History). Taylor and Francis. Kindle Edition.

James, Henry. The Turn of the Screw. Edited by Deborah Esch and Jonathan Warren, $2^{\text {nd }}$ ed.,W.W.Norton, 1999.

Kidd, Kenneth B."T Is for Trauma: The Children's Literature of Atrocity." Freud in Oz: At the Intersections of Psychoanalysis and Children's Literature, NED - New edition ed., University of Minnesota Press, Minneapolis; London, 2011, pp. 181206. JSTOR, www.jstor.org/stable/10.5749/j.ctttv88k.9.

Nikaeen, Mojtaba \& Bagheri, Ghodratollah. "Organizational Silence (Basic Concepts and Its Development Factors)." Ideal Type of Management. 2012.

Peterson, M. Jeanne. "The Victorian Governess: Status Incongruence in Family and Society." Victorian Studies, vol. 14, no. 1, 1970, pp. 7-26. JSTOR, www.jstor.org/stable/3826404. 
Wilson, Edmund. "The Ambiguity of Henry James." The Triple Thinkers. London: John Lehmann, 1952, 89-128. Internet Archive

https://archive.org/details/in.ernet.dli.2015.183272/page/n127/mode/2up. 